\begin{tabular}{l} 
Sharif University of Technology \\
Scientia Iranica \\
SCIENTIA \\
IRAN \\
Thansactions A: Civil Engineering \\
\hline
\end{tabular}

\title{
Seismic performance of EBFs equipped with an innovative shape memory alloy damper
}

\author{
N.M. Mirzai and R. Attarnejad* \\ School of Civil Engineering, College of Engineering, University of Tehran, Tehran, P.O. Box 4563-11155, Iran.
}

Received 8 May 2018; received in revised form 11 September 2018; accepted 3 December 2018

\section{KEYWORDS}

Shape memory alloys;

Damper;

Residual drift;

Eccentrically braced

frames.

\begin{abstract}
Given their unique characteristics, Shape Memory Alloys (SMAs) have significant potential for use in different areas of engineering. The phase shift characteristics of these alloys allow them to memorize a certain shape and, if deformed, they revert to that shape through a thermal process. Given the vast potentials of SMAs, they can be utilized to address the limitation of conventional Eccentrically Braced Frames (EBFs) with vertical links in order to achieve better residual and maximum interstory drifts. This paper introduced a vibration control system equipped with SMAs to achieve an improved operational domain. Compared to conventional EBFs, the proposed system named Recentering Damping Device (RDD) is easy to fabricate and implement and allows for redesigning fuse members. A numerical analysis of a 9-story steel frame building was performed using nonlinear analysis program, OpenSees, to evaluate the system performance. Results of time history analysis demonstrated better self-centering behavior and lower residual interstory drifts of the proposed system than EBF.
\end{abstract}

(C) 2020 Sharif University of Technology. All rights reserved.

\section{Introduction}

Eccentrically Braced Frames (EBFs) are lateral forceresisting systems that provide not only desirable elastic stiffness but also manageable inelastic behavior realized through controlled deformation of the link member under heavy loads such as earthquake motion. The history of research on the subject of controlled deformation under seismic loads can be traced back to the works published about three decades ago in [1-3].

The most important disadvantage of horizontal EBFs is the difficulty of repairing a deformed link member. To resolve this issue, researchers such as Aristizabal-Ochoa [4], Ghobarah and Abou Elfath [5],

\footnotetext{
*. Corresponding author.

E-mail address: attarnjd@ut.ac.ir (R. Attarnejad)
}

doi: $10.24200 /$ sci.2018.50990.1955 and Vetr et al. [6] proposed the application of vertical EBFs, in which a shear panel served as a vertical link between the story beam and the $\wedge$-shaped braces. This approach not only facilitates the repairing of damaged links but also makes the repairing easier in their horizontal counterpart. This approach also provides a convenient solution to the problematic cases where the presence of extensive gravity loads necessitates ensuring that floor beams remain in the elastic region. The disadvantage of this approach is the difficulty to provide lateral bracing for vertical links [7].

Shape Memory Alloy (SMA) is an alloy that can memorize a certain shape and, if deformed, recover the memorized shape when heated. SMAs have extensive potential for use in several industries, particularly in structures, automobiles, and aerospace vehicles [8]. Given the superelastic behavior, recentering ability, and damping capacity of SMAs, their potential use in the vibration control of structures has been the subject 
of many studies [9-26]. A comprehensive review of civil engineering applications of SMAs can be found in $[27,28]$. Regardless of their potential, applying these alloys to real structures needs an in-depth understanding of their mechanical behavior in different scenarios, which still requires further research [29]. This is also true in the case of EBFs, given that possible behaviors of SMAs in these frames are still under investigation [23].

In passive vibration control schemes, energy dissipation mechanisms are expected to reduce the demand on the primary structural members as well as any consequent plastic deformation. Meanwhile, the recentering mechanism attempts to return the structures to its original geometry, thereby preventing the aggregation of inelastic deformations [30]. The problem of applying SMAs to EBFs is the low energy dissipation capacity of recentering mechanisms, especially under high rate loadings, which is hard to reconcile with almost completely linear elastic behavior of SMAs. One approach to resolving this issue is the use of Nitinol-based devices proposed by Dolce et al. [31,32], which provides a good combination of recentering capability and energy dissipation. Some other researchers demonstrated that the combination of base isolation and SMA led to more structural integrity and concluded that re-centering Lead Rubber Bearing (LRB) isolators enhanced the seismic performance in terms of energy dissipation and re-centering influence (e.g. [33]).

Haque and Alam [34] presented a piston-based bracing that could perform recentering after large deformation. DesRoches et al. investigated the application of SMA bars to the beam-to-column connections of steel moment-resisting frames and the seismic performance of the resulting system [35]. Ellingwood et al. studied the seismic demand of steel momentresisting frames with SMA connections, but they used a probabilistic seismic demand assessment approach for this purpose [36]. The application of SMAs to the vibration control systems typical of other domains of civil engineering was also researched [23,37-41]. Moreover, several researchers have employed the special properties of SMAs to improve the response of structures. For example, in the references [16,23,41,42], it can be seen that the application of SMAs could significantly reduce the response of structures in terms of interstory drift ratios, residual drifts, and absolute acceleration of floors.

This paper proposes a recentering damper with enhanced self-centering and energy dissipation capabilities, which is simple to set up and can be utilized for the seismic design of new structures as well as retrofitting of existing structures. This paper also provides the results of the tests conducted to determine the impact of displacement amplitude and frequency on the mechanical behavior of the device, and the shaking table tests were carried out to evaluate its ability to control the seismic response.

\section{SMA characteristics}

\subsection{Phase transformations}

SMAs have two stable phases. The first phase, martensite, is the state where alloy has high stress and low temperature, and the second phase, austenite, is the state where alloy has low stress and high temperature. Martensite phase itself has two variants: twinned and detwinned. Therefore, a change in stress, temperature, or both can trigger phase transformation in the case of these alloys. The strain corresponding to the phase transformation is called transformation strain. In Figure 1 , the transformation fronts are portrayed on the $T-\sigma$ plane. The phase transformation is the source of Shape Memory Effect (SME) and pseudoelasticity that make SMAs a fascinating and potentially rewarding subject of research. Researchers such as reference [43] have identified more phases for SMAs to model other effects, but this is beyond the scope of the present paper.

\subsection{Shape Memory Effect (SME)}

SME can be described as a process in which SMA memorizes a shape and, then, recovers that shape when heated. As shown in Figure 2, this effect is realized in the four following stages:

1. Stress application: Subjecting the alloy to stress rearranges the twinned martensite into detwinned martensite, but leaves a transformation strain;

2. Stress removal: Removing the stress eliminates the elastic strain, but not the transformation strain, as the alloy remains in the detwinned martensite phase;

3. Heat application: Once heated, the alloy undergoes a phase shift from martensite to austenite,

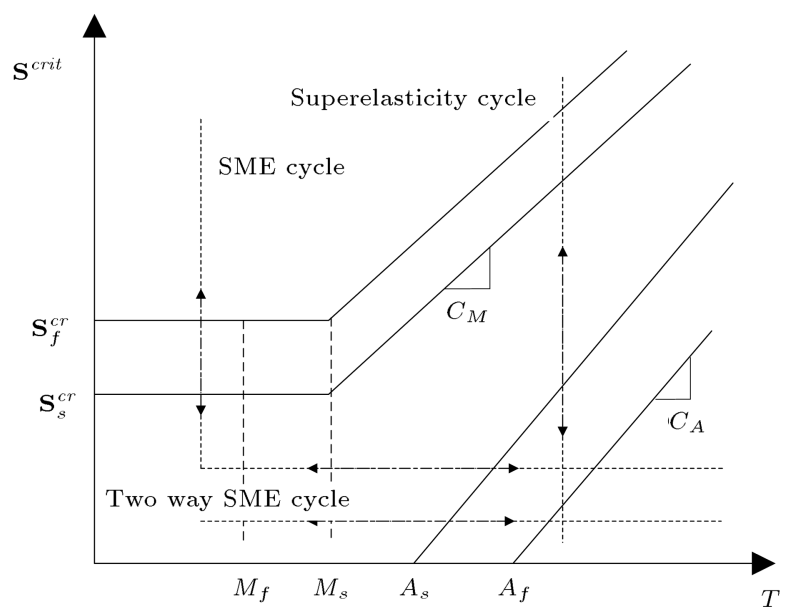

Figure 1. Transformation fronts portrayed on the $T-\sigma$ plane [44]. 

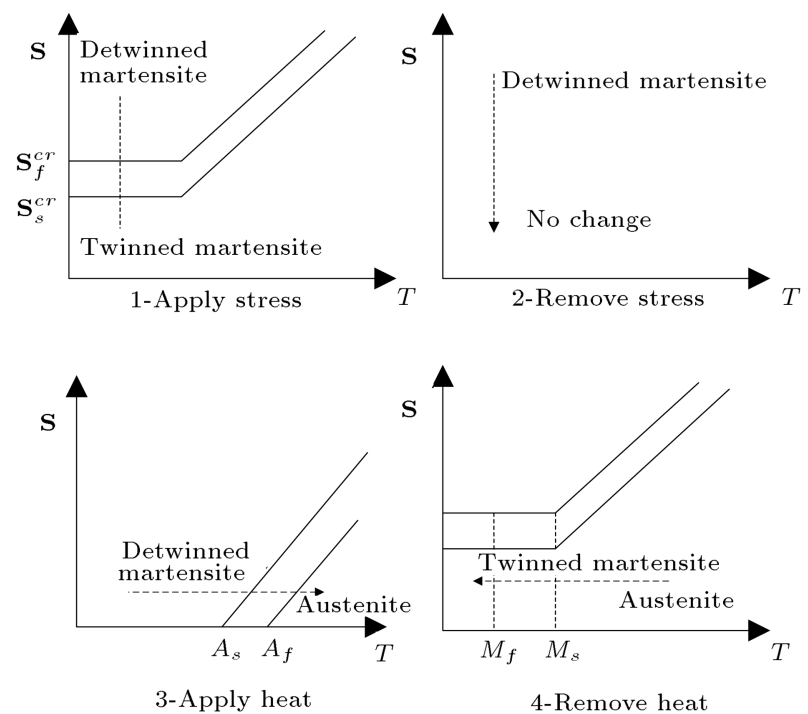

Figure 2. Shape Memory Effect (SME) [44].

which results in the recovery of transformation strain;

4. Heat removal: After removing the heat, the alloy undergoes another phase shift from austenite to twinned martensite.

At the end of the fourth stage, the plastic strain will be removed and the alloy will recover its initial strain state.

\section{Device configuration and mechanism}

The mechanical layout of the SMA-reinforced lead rubber damper is displayed in Figure 3. As can be seen, the Recentering Damping Device (RDD) is a LRB equipped with SMA bars, top and bottom stiffeners that work in opposite directions, and steel plates that connect it at the top and bottom to the structure. Two yellow plates are in front of each other, but one has been installed on the top plate and the other one on the bottom plate. The yellow plates can get away and apply tensile force to the SMA bars. If the plates move away from each other, the device will create a tension force and flag-shaped hysteresis, which, alongside the hysteresis of the lead core, will result in significant energy dissipation. The plates moving toward each other will create no compression force in the bars, as they can slip into the slots embedded for this purpose.

The SMA bars are connected to the steel palates using nuts. Some researchers conducted experimental tests equipped with the SMA bars in their model using nuts (e.g. $[45,46])$.

\section{Verification study}

To ensure the accuracy of the modeling, all parts of the modeling have been verified by the experimental tests available in the literature. The verification study includes two different parts:

1. An Single-Degree-Of-Freedom (SDOF) vertical shear link studied by Bouwkamp et al. [47];

2. Modeling of the SMA material tested by Desroches et al. [48].

More details are addressed in the following.

\subsection{Verification study of an SDOF vertical shear link}

A one-story vertical shear link is subjected to cyclic loading in which two cycles are applied at displacement levels of $\pm 1.5 \mathrm{~mm}, \pm 2.0, \pm 3.0, \pm 3.5, \pm 4.0, \pm 5.0, \pm 6.0$, $\cdots, \pm 10.0, \pm 12.0, \cdots, \pm 34.0$. The details of the SDOF frame are shown in Table 1. Figure 4 illustrates good agreement between the results of the experimental test and OpenSees.

\subsection{Verification study of SMA behavior}

To evaluate the accuracy of the simulation of the SMA bar in OpenSees platform, the behavior of the material was verified by Desroches et al. [48]. Figure 5 shows a comparison between an SMA bar with $25.4 \mathrm{~mm}$ diameter and OpenSees, demonstrating that the parameters applied to the numerical model have been adopted accurately.
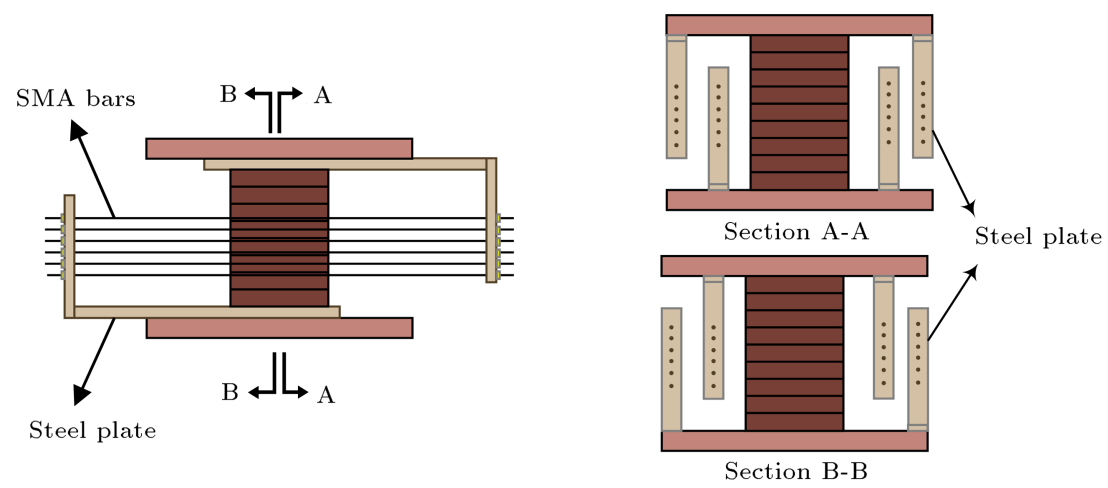

Figure 3. Configuration of the Recentering Damping Device (RDD). 
Table 1. The details of the SDOF frame tested by Bouwkamp et al. [47].

\begin{tabular}{cccccc}
\hline $\begin{array}{c}\text { Specimen } \\
\text { no. }\end{array}$ & $\begin{array}{c}\text { Beam } \\
\text { section }\end{array}$ & $\begin{array}{c}\text { Vertical shear } \\
\text { link section }\end{array}$ & $\begin{array}{c}\text { Shear link length, } \\
\boldsymbol{e}(\mathbf{m m})\end{array}$ & $\begin{array}{c}\text { Column } \\
\text { section }\end{array}$ & $\begin{array}{c}\text { Brace } \\
\text { section }\end{array}$ \\
\hline 3 & HEA320 & HEA280 & 300 & 2 UPN140 & 2UPN220 \\
\hline
\end{tabular}

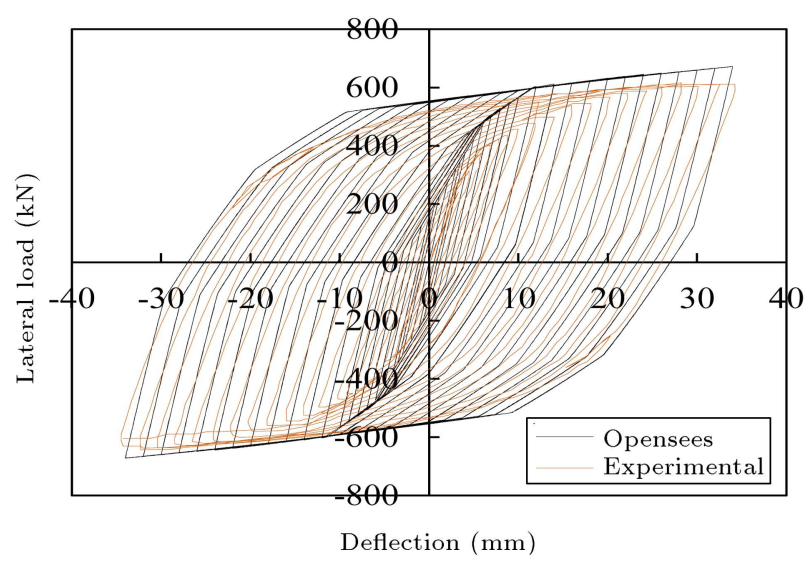

Figure 4. The comparison between the results obtained from OpenSees and experimental test [47].

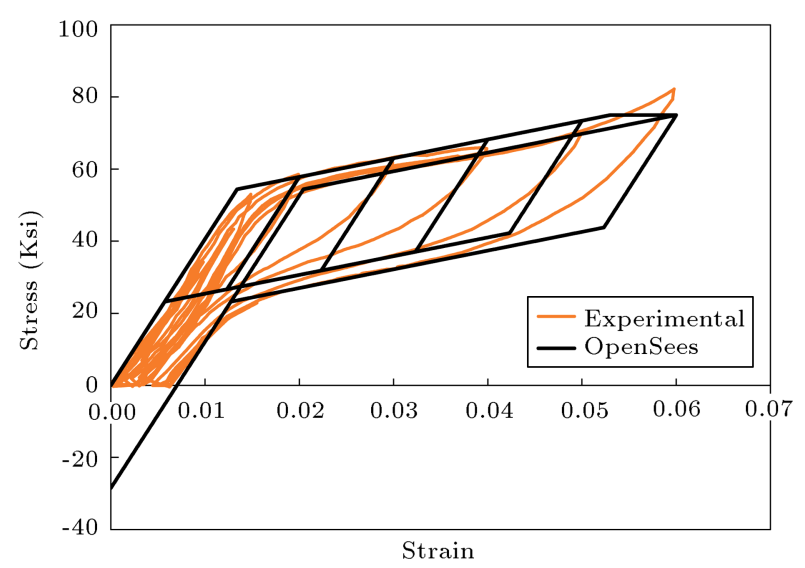

Figure 5. The comparison of Shape Memory Alloy (SMA) behaviors of OpenSees and experimental test [48].

\section{Frame design and modeling}

The performance of the system was evaluated using the models of 9-story steel buildings designed for a seismically active site (Tehran) composed of soil type III with $V_{S} 30=175-375 \mathrm{~m} / \mathrm{s}$ according to Iranian code of practice for seismic-resistant design of buildings [49]. Every story was assumed to have a height of $3.2 \mathrm{~m}$. Buildings were designed using the gravity loads typically assumed for residential buildings in Iran. An image of the designed structures is shown in Figure 6. The specifications of the buildings are provided in Table 2. To ensure a reasonable comparison, the natural period of both systems should be almost the same. Attempts have been made to keep the natural period of the RDD system close to the conventional EBF by controlling the amount of SMA in the structure. The natural periods of the conventional structure and the RDD braced frame are $1.0 \mathrm{sec}$ and $0.94 \mathrm{sec}$, respectively.

The buildings were modeled and analyzed by using OpenSees software. All models were simulated based on a verified model in OpenSees $[47,50]$. Internal frame of all structures was subjected to $2 \mathrm{D}$ nonlinear static and dynamic analyses. Steel behavior was modeled using OpenSees material library by assigning the elements with a desired bilinear kinematic stress-strain curve. To ensure that there would be no jump in local stiffness of elements or the transition between elastic and plastic regions, a transition curve was defined for the tangent moduli (the intersection of the first and second tangents). Beam and column cross-sections

Table 2. The structural details of nine-story IY-shaped brace frames.

\begin{tabular}{|c|c|c|c|c|c|c|c|c|}
\hline \multirow[b]{3}{*}{ Frame } & \multirow[b]{3}{*}{ Story no. } & \multicolumn{6}{|c|}{ Section } & \multirow{3}{*}{$\begin{array}{c}\text { Link } \\
\text { length } \\
(\mathrm{mm})\end{array}$} \\
\hline & & \multicolumn{2}{|c|}{ Beam } & \multicolumn{2}{|c|}{ Column } & \multirow{2}{*}{ Brace } & \multirow{2}{*}{ Link } & \\
\hline & & B1 & B2 & $\mathrm{C} 1$ & $\mathrm{C2}$ & & & \\
\hline \multirow{6}{*}{9 -story } & 1 & IPE360 & IPE240 & Box $180 \times 180 \times 10$ & Box $240 \times 240 \times 20$ & 2UPN280 & IPE360 & 480 \\
\hline & 2 and 3 & IPE360 & IPE240 & Box $180 \times 180 \times 10$ & Box $240 \times 240 \times 20$ & 2UPN280 & IPE330 & 480 \\
\hline & 4 & IPE360 & IPE240 & Box $180 \times 180 \times 10$ & Box $220 \times 220 \times 20$ & 2UPV240 & IPE330 & 480 \\
\hline & 5 & IPE360 & IPE240 & Box $180 \times 180 \times 10$ & Box $220 \times 220 \times 20$ & 2UPV240 & IPE270 & 480 \\
\hline & 6 and 7 & IPE360 & IPE240 & Box $180 \times 180 \times 10$ & Box $160 \times 160 \times 20$ & 2UPN180 & IPE200 & 350 \\
\hline & 8 and 9 & IPE360 & IPE240 & Box $180 \times 180 \times 10$ & Box $160 \times 160 \times 20$ & 2UPN180 & IPE200 & 350 \\
\hline
\end{tabular}



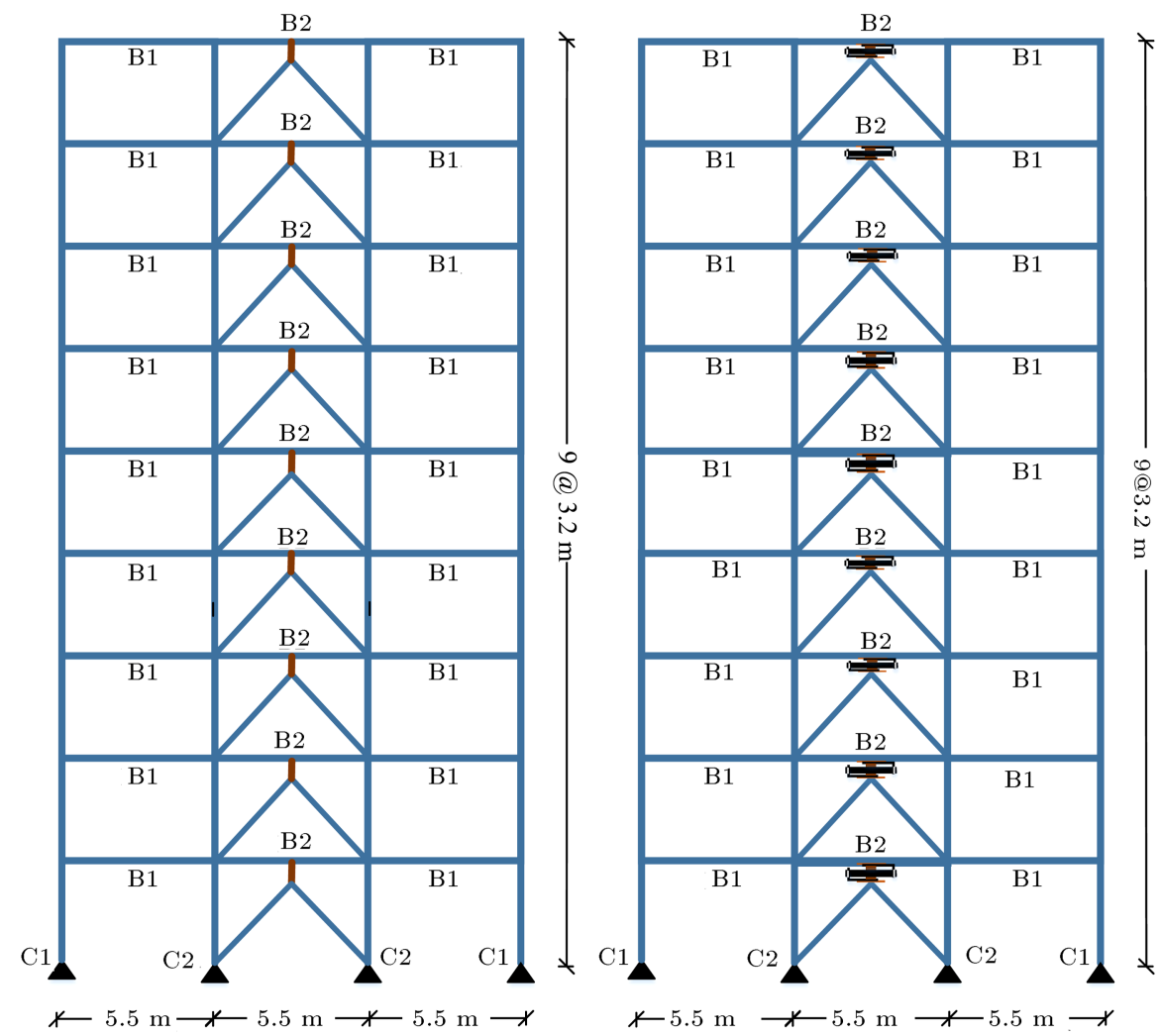

Figure 6. Elevations and spans of building.

were modeled using a combination of displacementbased beam-columns and fiber sections. According to $[51,52]$, force-based elements are characterized by inherently lower stability than displacement-based elements. In the software, P-delta transformation of geometrical stiffness matrix was used to make sure that P-delta effects were incorporated into the analysis.

The details of the LRB used in the nine-story building are listed in Table 3 .

Herein, $V$ is the vertical load, $K_{e}$ is effective horizontal stiffness, $x_{e}$ is equivalent viscous damping coefficient, $d_{1}, F_{1}, d_{2}, F_{2}$ define the bilinear curves, $D_{g}$ is external elastomer diameter, $t_{e}$ is total elastomer thickness, $h$ is height excluding outer steel plates, $H$ is total height including outer steel plates, and $Z$ is side length of outer steel plate. According to Table 3, the proposed hybrid device in this paper has a damping ratio of $29 \%$, which leads to a considerable reduction in the response of the structure.

Ricles and Popov [54] recommended that a form of nonproportional viscous damping should be employed to prevent unrealistic, larger axial forces in braces and columns besides the shear links. To this end, they recommended that Rayleigh damping was applied to all members except shear links. In this paper, this recommendation was employed such that the "Rayleigh Damping Command" in OpenSees was assigned to all elements except the shear links using "Region Command".

\section{Performance assessment}

The lateral load-carrying capacity was evaluated by applying lateral loads to the models both statically and dynamically.

\subsection{Pushover curve}

The lateral strength and post-yield behavior were assessed through static pushover analysis. Figure 7 presents the base shear versus maximum roof displacement pushover diagram obtained for the 9-story model. To ensure that the inherent response of the

Table 3. The details of Lead Rubber Bearing (LRB) in nine-story building [53].

\begin{tabular}{|c|c|c|c|c|c|c|c|c|c|c|c|c|}
\hline LRB-S & $\begin{array}{c}V \\
(\mathrm{kN})\end{array}$ & $\begin{array}{c}\boldsymbol{K}_{e} \\
(\mathrm{kN} / \mathbf{m m})\end{array}$ & $\begin{array}{l}x_{e} \\
(\%)\end{array}$ & $\begin{array}{c}F_{2} \\
(\mathrm{kN})\end{array}$ & $\begin{array}{c}F_{1} \\
(\mathrm{kN})\end{array}$ & $\begin{array}{c}d_{1} \\
(\mathrm{~mm})\end{array}$ & $\begin{array}{c}d_{2} \\
(\mathrm{~mm})\end{array}$ & $\begin{array}{c}D_{g} \\
(\mathbf{m m})\end{array}$ & $\begin{array}{c}t_{e} \\
(\mathrm{~mm})\end{array}$ & $\begin{array}{c}h \\
(\mathrm{~mm})\end{array}$ & $\begin{array}{c}H \\
(\mathrm{~mm})\end{array}$ & $\begin{array}{c}Z \\
(\mathrm{~mm})\end{array}$ \\
\hline $\begin{array}{c}\text { LRB-S } \\
800 / 128-130\end{array}$ & 10310 & 3.2 & 29 & 267 & 155 & 10 & 83 & 800 & 128 & 223 & 283 & 850 \\
\hline
\end{tabular}



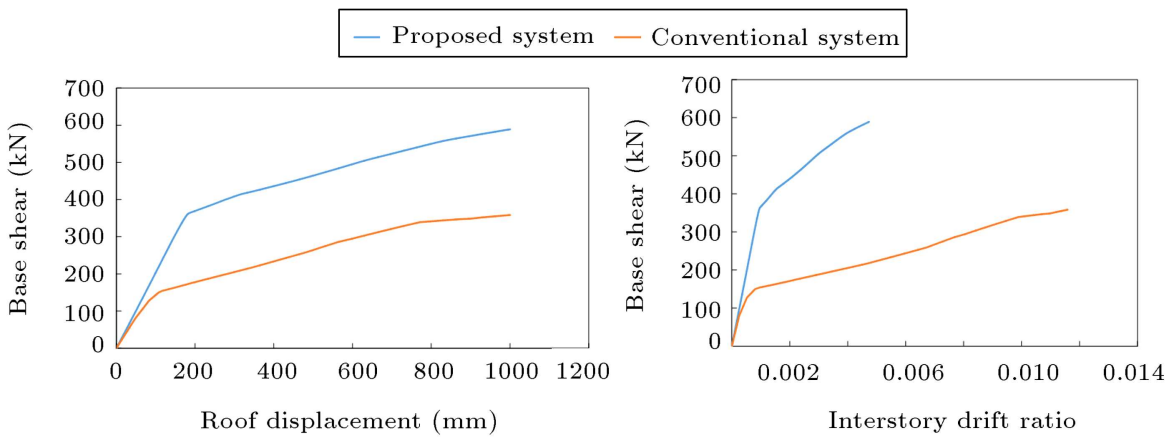

Figure 7. Pushover curves in terms of roof displacement and interstory drift ratio.

building to lateral loading was accounted for, a load pattern based on the structure's fundamental period was used to apply loading in a displacement-controlled state.

These results demonstrate that the proposed system has better performance due to its higher capacity.

\subsection{Nonlinear time history analysis}

Beyond the nonlinear static analyses, nonlinear response history analyses were carried out to further evaluate the inter-story drift responses of the system. This section discusses maximum inter-story drifts, maximum residual inter-story drifts, and residual displacement obtained from the nonlinear response history analyses of systems with and without the proposed damper.

To conduct the nonlinear time history analysis, ten far-field records were selected from FEMAP695 at magnitudes of $6.5-7.5$. All the ground motion time histories were scaled to $0.55 \mathrm{~g}$ based on a method suggested by Iranian code of practice for the seismicresistant design of buildings [49]. Figure 8 shows the scaling procedure according to Iranian seismic code. In addition, the considered soil type for Iran is $D$ (stiff soils) based on Geomatrix soil class in USGS (US Geological Survey). The details of the used ground motions are specified in Table 4 .

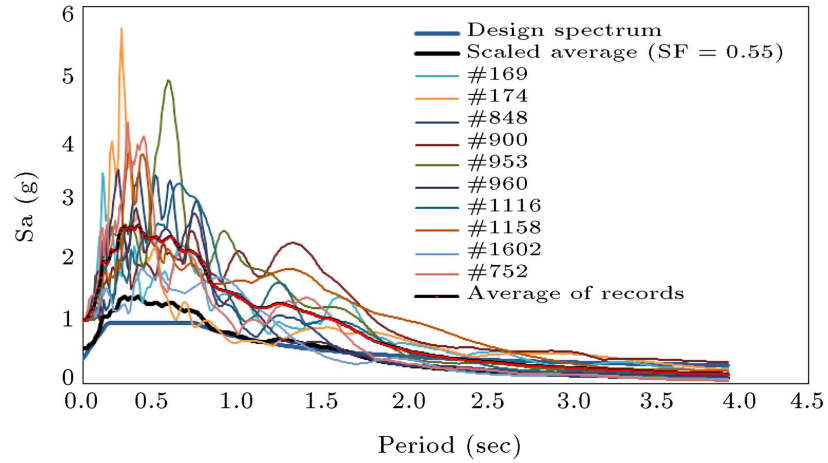

Figure 8. Spectral acceleration for scaling the ground motions.

\subsubsection{Maximum interstory drift ratio}

Global and local interstory deformations are one of the causes of damage induced to the structure. Even elastic deformation of the structure may induce some damage to the nonstructural components. Therefore, greater deformation will cause not only nonstructural damage but also the series structural damage. Figure 9 shows that the maximum interstory drift has been reduced to $57 \%$.

The response of the 9-story building subjected to one ground motion (record seq. no. 900 in Table 4) is shown in Figure 10 as an example.

Table 4. Far-field ground motions from FEMA P695.

\begin{tabular}{|c|c|c|c|c|c|c|c|}
\hline $\begin{array}{l}\text { Record } \\
\text { seq. no. }\end{array}$ & $\begin{array}{l}V_{s \_30} \\
(\mathrm{~m} / \mathrm{s})\end{array}$ & $\begin{array}{c}\text { NEHRP } \\
\text { class }\end{array}$ & Year & Name & $\begin{array}{c}\text { Recording } \\
\text { station }\end{array}$ & Magnitude & PGA $(g)$ \\
\hline 953 & 356 & $\mathrm{D}$ & 1994 & Northridge & Beverly Hills-Mulhol & 6.7 & 0.52 \\
\hline 960 & 309 & $\mathrm{D}$ & 1994 & Northridge & Canyon Country-WLC & 6.7 & 0.48 \\
\hline 1602 & 326 & $\mathrm{D}$ & 1999 & Duzce, Turkey & Bolu & 7.1 & 0.82 \\
\hline 169 & 275 & $\mathrm{D}$ & 1979 & Imperial Valley & Delta & 6.5 & 0.35 \\
\hline 174 & 196 & $\mathrm{D}$ & 1979 & Imperial Valley & El Centro Array\#11 & 6.5 & 0.38 \\
\hline 1116 & 256 & $\mathrm{D}$ & 1995 & Kobe, Japan & Shin-Osaka & 6.9 & 0.254 \\
\hline 1158 & 276 & $\mathrm{D}$ & 1999 & Kocaeli, Turkey & Ducze & 7.5 & 0.36 \\
\hline 900 & 354 & $\mathrm{D}$ & 1992 & Landers & Yermo Fire Station & 7.3 & 0.24 \\
\hline 848 & 271 & $\mathrm{D}$ & 1992 & Landers & Coolwater & 7.3 & 0.42 \\
\hline 752 & 289 & $\mathrm{D}$ & 1989 & Loma Perieta & Capitola & 6.9 & 0.53 \\
\hline
\end{tabular}




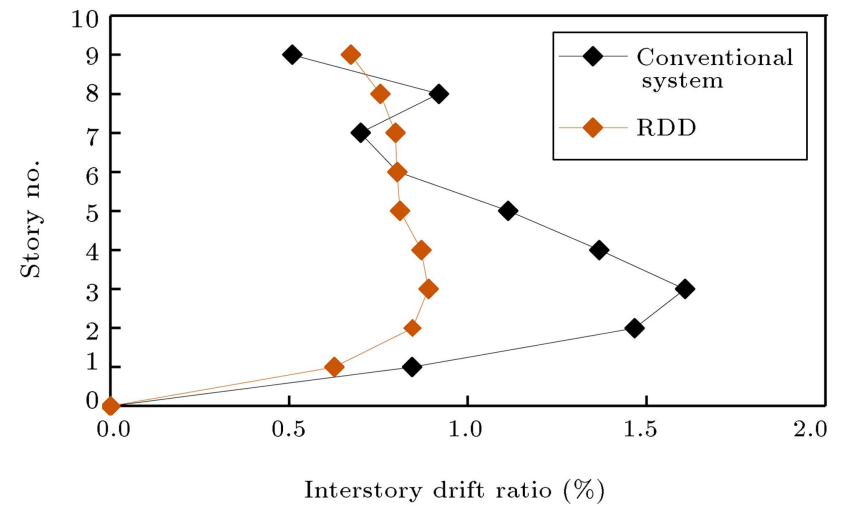

Figure 9. The average of maximum interstory drift ratio subjected to the ten ground motion records.

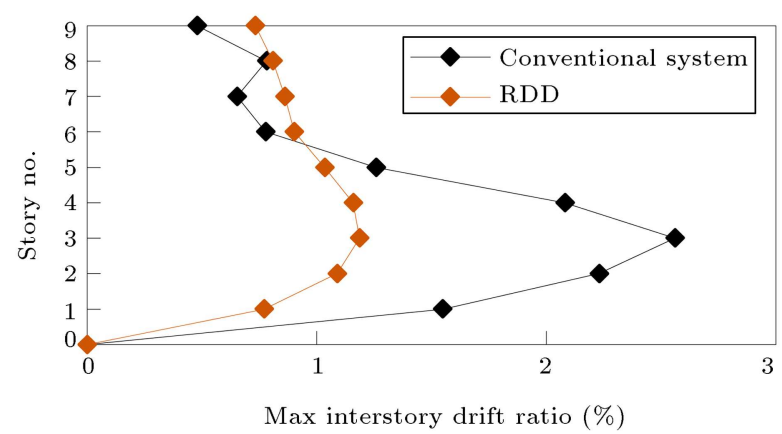

Figure 10. Comparison of maximum interstory drift ratio in two cases (with and without Recentering Damping Device (RDD)) subjected to the ground motion \#900.

\subsubsection{Residual drift}

The inelastic deformation caused under earthquake loads may lead to significant residual deformation which increases the time and cost of the structure repair and, in some cases, leads to partial or total collapse or unusability of structure. As can be seen in Figures 11 and 12, the RDD device can significantly decrease the residual drift in the 9-story building. Figure 12 shows the residual drift of the two structures under Landers earthquake (see Table 4). The recentering effect can be clearly seen in Figure 12. Based on this figure, the 9-story conventional building is not usable after the earthquake and will probably collapse, partially or totally. However, in the RDD braced frame, the maximum residual drift of the 9-story building is almost $0.2 \%$; therefore, considering rehabilitation is reasonable and affordable.

\subsubsection{Residual displacement}

Residual displacement has an important role in judging the post-earthquake safety of buildings and in decision on the economic possibility of repair and reconstruction. Figure 13 illustrates the effect of the RDD device on mitigation of the residual displacement. As can be seen in Figure 13, the residual displacement has decreased. Moreover, residual displacement is more

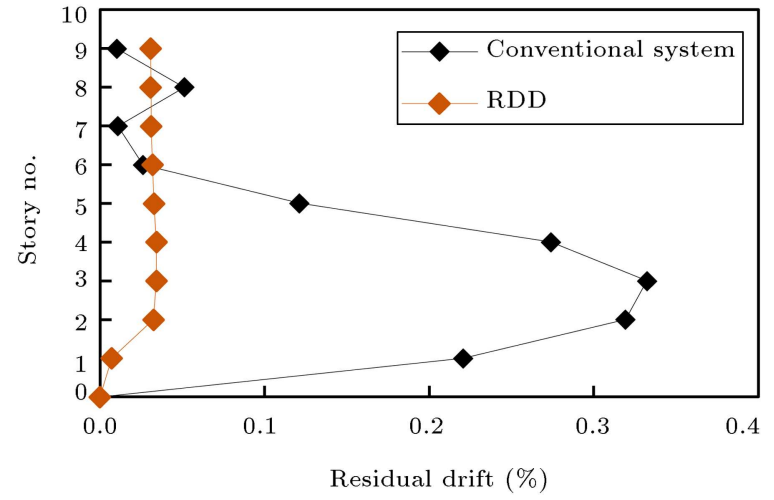

Figure 11. The average of residual drift subjected to ten ground motion records.

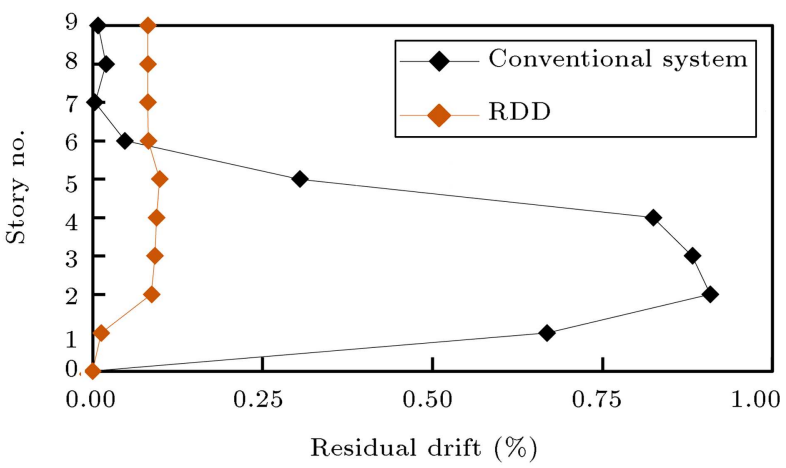

Figure 12. Comparison of residual drift in two cases (with and without Recentering Damping Device (RDD)) subjected to ground motion \#900.

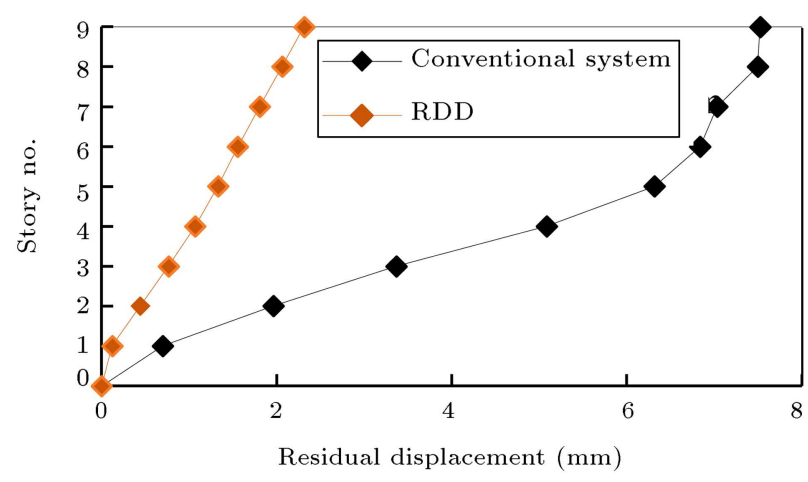

Figure 13. Residual displacement for ten ground motion records.

uniform in the case of both buildings. Time history response of the buildings is shown in Figure 14. It can be observed that the RDD device has a significant role in reducing the residual displacement of the structures. Uniform drift corresponds to uniform demand capacity stiffness ratios [55].

\section{Conclusions}

A Recentering Damping Device (RDD) including an Eccentrically Braced Frame (EBF) equipped with 

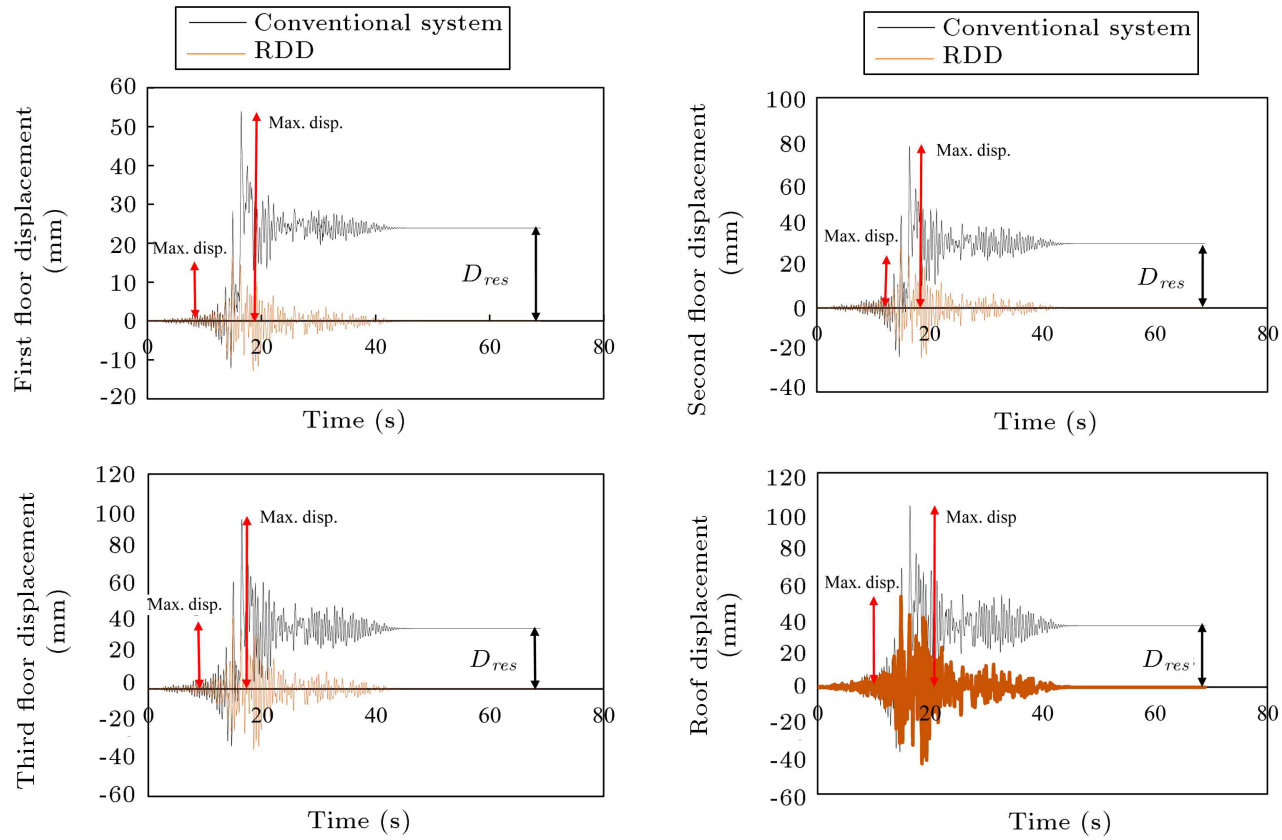

Figure 14. Displacement time history for record \#900.

Shape Memory Alloy (SMA) that acts as a rapid repair fuse was proposed and numerically evaluated in this study. A nine-story steel frame was considered by using numerical models. A nonlinear time history analysis was conducted using 10 different ground motions simulated in the OpenSees platform. The main findings of the present study are summarized as follows:

1. The simulation results illustrated that RDD could reduce the maximum inter-story drift ratio by $57 \%$ in the nine-story building;

2. Compared to conventional EBFs, the RDD system effectively reduced residual drift by up to $86.99 \%$ for the nine-story buildings at different ground motion records;

3. The RDD system also produced minimal residual displacement for all of the ten ground motion records;

4. Considerably lower residual drifts observed in the proposed RRD system demonstrated that the repair costs of the steel buildings equipped with RRD were lower than those of the traditional steel frames after an earthquake;

5. The pushover curve showed that the RRD system had larger capacity than the conventional system;

6. Although SMA materials was expensive, their cost could be kept quite modest by using reasonably priced materials.

\section{References}

1. Lian, M. and Su, M. "Seismic performance of highstrength steel fabricated eccentrically braced frame with vertical shear link", Journal of Constructional Steel Research, 137, pp. 262-285 (2017).

2. Chegeni, B. and Mohebkhah, A. "Rotation capacity improvement of long link beams in eccentrically braced frames", Scientia Iranica, 21(3), pp. 516-524 (2014).

3. Pourzeynali, S. and Shakeri, A. "A comparative study on the ductility and energy dissipation capacity of SMRF and V-EBF systems", Scientia Iranica, 22(4), pp. 1470-1480 (2015).

4. Aristizabal-Ochoa, J.D. "Disposable knee bracing: Improvement in seismic design of steel frames", Journal of Structural Engineering, United States, 112(7), pp. 1544-1552 (1986).

5. Ghobarah, A. and Abou Elfath, H. "Rehabilitation of a reinforced concrete frame using eccentric steel bracing", Engineering Structures, 23(7), pp. 745-755 (2001).

6. Vetr, M.G., Ghamari, A., and Bouwkamp, J. "Investigating the nonlinear behavior of eccentrically braced frame with vertical shear links (V-EBF)", Journal of Building Engineering, 10, pp. 47-59 (2017).

7. Kazemzadeh, A. and Topkaya, C. "A review of research on steel eccentrically braced frames", Journal of Constructional Steel Research, 128, pp. 53-73 (2017).

8. Chang, W.S. and Araki, Y. "Use of shape-memory alloys in construction: A critical review", Proceedings of the Institution of Civil Engineers: Civil Engineering, 169(2), pp. 87-95 (2016).

9. Araki, Y., Maekawa, N., Shrestha, K.C., Yamakawa, M., Koetaka, Y., Omori, T., and Kainuma, R. "Fea- 
sibility of tension braces using $\mathrm{Cu}-\mathrm{Al}-\mathrm{Mn}$ superelastic alloy bars", Structural Control and Health Monitoring, 21(10), pp. 1304-1315 (2014).

10. Fanaiea, N. and Monfared, M.N. "Cyclic behavior of extended end-plate connections with shape memory alloy bolts", Structural Engineering and Mechanics, 60(3), pp. 507-527 (2016).

11. Hu, J.W., Smart Connection Systems: Design and Seismic Analysis, CRC Press (2015).

12. Hu, J.W. "Seismic performance evaluations and analyses for composite moment frames with smart SMA PRCFT connections", PhD Thesis, Georgia Tech. (2008).

13. Iwamoto, T. and Cao, B. "A review on experimental investigations of rate sensitivity of deformation behavior in Fe-based shape memory alloys", Advanced Structured Materials, 73, pp. 31-42 (2017).

14. Kari, A., Ghassemieh, M., and Abolmaali, S.A. "A new dual bracing system for improving the seismic behavior of steel structures", Smart Materials and Structures, 20(12), pp. 1-14 (2011).

15. Miller, D.J., Fahnestock, L.A., and Eatherton, M.R. "Development and experimental validation of a nickeltitanium shape memory alloy self-centering bucklingrestrained brace", Engineering Structures, 40, pp. 288298 (2012).

16. Moradi, S., Alam, M.S., and Asgarian, B. "Incremental dynamic analysis of steel frames equipped with NiTi shape memory alloy braces", Structural Design of Tall and Special Buildings, 23(18), pp. 1406-1425 (2014).

17. Rofooei, F.R. and Yadegari Farzaneh, A. "Numerical study of an innovative SMA based beam-column connection in reducing the seismic response of steel MRF structures", Scientia Iranica, 23(5), pp. 20332043 (2016).

18. Sayyaadi, H., Zakerzadeh, M.R., and Salehi, H. "A comparative analysis of some one-dimensional shape memory alloy constitutive models based on experimental tests", Scientia Iranica, 19(2), pp. 249-257 (2012).

19. Silwal, B., Michael, R.J., and Ozbulut, O.E. "A superelastic viscous damper for enhanced seismic performance of steel moment frames", Engineering Structures, 105, pp. 152-164 (2015).

20. Speicher, M.S., DesRoches, R., and Leon, R.T. "Experimental results of a NiTi shape memory alloy (SMA)-based recentering beam-column connection", Engineering Structures, 33(9), pp. 2448-2457 (2011).

21. Speicher, M.S., DesRoches, R., and Leon, R.T. "Investigation of an articulated quadrilateral bracing system utilizing shape memory alloys", Journal of Constructional Steel Research, 130, pp. 65-78 (2017).

22. Walter Yang, C.S., DesRoches, R., and Leon, R.T. "Design and analysis of braced frames with shape memory alloy and energy-absorbing hybrid devices", Engineering Structures, 32(2), pp. 498-507 (2010).

23. Qiu, C., Zhang, Y., Li, H., Qu, B., Hou, H., and Tian, L. "Seismic performance of Concentrically
Braced Frames with non-buckling braces: A comparative study", Engineering Structures, 154, pp. 93-102 (2018).

24. Ren, W., Li, H., and Song, G. "An innovative shape memory alloy damper for passive control of structures subjected to seismic excitations", Proc., The 14th World Conference on Earthquake Engineering (2008).

25. Sultana, P. "Enhancing the seismic performance of steel structures utilizing superelastic shape memory alloys", PhD Thesis, The University of Western Ontario (2016).

26. Nunes, J.M.M. "Adaptive tuned mass damper (ATMD) based in shape-memory alloy (SMA) elements", MSc Thesis, Nova University of Lisbon (2016).

27. Ozbulut, O.E., Hurlebaus, S., and Desroches, R. "Seismic response control using shape memory alloys: A review", Journal of Intelligent Material Systems and Structures, 22(14), pp. 1531-1549 (2011).

28. Song, G., Ma, N., and Li, H.N. "Applications of shape memory alloys in civil structures", Engineering Structures, 28(9), pp. 1266-1274 (2006).

29. Ozbulut, O.E. "Neuro-fuzzy model of superelastic shape memory alloys with application to seismic engineering", MSc Thesis, Texas A\&M University (2007).

30. Motahari, S.A., Ghassemieh, M., and Abolmaali, S.A. "Implementation of shape memory alloy dampers for passive control of structures subjected to seismic excitations", Journal of Constructional Steel Research, 63(12), pp. 1570-1579 (2007).

31. Cardone, D., Dolce, M., Ponzo, F.C., and Coelho, E. "Experimental behaviour of R/C frames retrofitted with dissipating and RE-centring braces", Journal of Earthquake Engineering, 8(3), pp. 361-396 (2004).

32. Dolce, M., Cardone, D., Ponzo, F.C., and Valente, C. "Shaking table tests on reinforced concrete frames without and with passive control systems", Earthquake Engineering and Structural Dynamics, 34(14), pp. 1687-1717 (2005).

33. Moradi, S. and Alam, M.S. "Feasibility study of utilizing superelastic shape memory alloy plates in steel beam-column connections for improved seismic performance", Journal of Intelligent Material Systems and Structures, 26(4), pp. 463-475 (2015).

34. Haque, A.B.M.R. and Alam, M.S. "Cyclic performance of a piston based self-centering bracing system", Proc., Structures Congress 2015 - Proceedings of the 2015 Structures Congress, pp. 2360-2371 (2015).

35. DesRoches, R., Taftali, B., and Ellingwood, B.R. "Seismic performance assessment of steel frames with shape memory alloy connections. Part i analysis and seismic demands", Journal of Earthquake Engineering, 14(4), pp. 471-486 (2010).

36. Ellingwood, B.R., Taftali, B., and Desroches, R. "Seismic performance assessment of steel frames with shape memory alloy connections, part ii - Probabilistic seismic demand assessment", Journal of Earthquake Engineering, 14(5), pp. 631-645 (2010). 
37. Aryan, H. and Ghassemieh, M. "Mitigation of vertical and horizontal seismic excitations on bridges utilizing shape memory alloy system", Advanced Materials Research, pp. 90-94 (2014).

38. Jung, D. and Andrawes, B. "Seismic damage assessment of SMA-retrofitted multiple-frame bridge subjected to strong main shock-aftershock excitations", Journal of Bridge Engineering, 23(1), pp. 1-11 (2018).

39. Ozbulut, O.E. and Hurlebaus, S. "A comparative study on the seismic performance of superelasticfriction base isolators against near-field earthquakes", Earthquake Spectra, 28(3), pp. 1147-1163 (2012).

40. Varela, S. and Saiidi, M.S. "A bridge column with superelastic NiTi SMA and replaceable rubber hinge for earthquake damage mitigation", Smart Materials and Structures, 25(7), pp. 1-18 (2016).

41. Ozbulut, O.E. and Silwal, B. "Performance assessment of buildings isolated with S-FBI system under nearfault earthquakes", Smart Structures and Systems, 17(5), pp. 709-724 (2016).

42. Eatherton, M.R., Fahnestock, L.A., and Miller, D.J. "Computational study of self-centering bucklingrestrained braced frame seismic performance", Earthquake Engineering \& Structural Dynamics, 43(13), pp. 1897-1914 (2014).

43. Naito, H., Matsuzaki, Y. and Ikeda, T. "A unified constitutive model of phase transformations and rearrangements of shape memory alloy wires subjected to quasistatic load", Smart Materials and Structures, 13(3), pp. 535-543 (2004).

44. Leong, S.L. "Using shape memory alloy as dampers: methodology", MSc Thesis, Massachusetts Institute of Technology (2005).

45. Penar, B.W. "Recentering beam-column connections using shape memory alloys", PhD Thesis, Georgia Institute of Technology (2005).

46. Fang, C., Yam, M.C.H., Lam, A.C.C., and Xie, L. "Cyclic performance of extended end-plate connections equipped with shape memory alloy bolts", Journal of Constructional Steel Research, 94, pp. 122-136 (2014).

47. Bouwkamp, J., Vetr, M.G., and Ghamari, A. "An analytical model for inelastic cyclic response of eccentrically braced frame with vertical shear link (VEBF)", Case Studies in Structural Engineering, 6, pp. 31-44 (2016).

48. Desroches, R., McCormick, J., and Delemont, M. "Cyclic properties of superelastic shape memory alloy wires and bars", Journal of Structural Engineering, 130(1), pp. 38-46 (2004).

49. Iranian code of practice for seismic resistant design of buildings, IS 2800-14 (2014).
50. DesRoches, R., Mccormick, J., and Delemont, M. "Cyclic properties of superelastic shape memory alloy wires and bars", Journal of Structural Engineering, 130, pp. 38-46 (2004).

51. Asgarian, B., Sadrinezhad, A., and Alanjari, P. "Seismic performance evaluation of steel moment resisting frames through incremental dynamic analysis", Journal of Constructional Steel Research, 66(2), pp. 178190 (2010).

52. Neuenhofer, A. and Filippou, F.C. "Evaluation of nonlinear frame finite-element models", Journal of Structural Engineering, 123(7), pp. 958-966 (1997).

53. Tanaka, K. and Sasaki, Y. "Hysteretic performance of shear panel dampers of ultra low yield-strength steel for seismic response control of buildings", 12th World Conference on Earthquake Engineering 12 wcee 2000

54. Ricles, J.M. and Popov, E.P. "Inelastic link element for EBF seismic analysis", Journal of Structural Engineering, 120(2), pp. 441-463 (1994).

55. Grigorian, M., Moghadam, A.S., and Mohammadi, H. "Advances in rocking core-moment frame analysis", Bulletin of Earthquake Engineering, 15(12), pp. 55515577 (2017).

\section{Biographies}

Nadia M. Mirzai received her BSc degree in Civil Engineering from Shahid Bahonar University of Kerman in 2009 and MSc degree in Structural Engineering from Shiraz University in 2011. She is currently a PhD candidate of Structural Engineering in University of Tehran, working in fields such as applications of smart materials in earthquake engineering and passive control systems. Ten contributions have been published by her in international journals and conferences.

Reza Attarnejad received his $\mathrm{PhD}$ degree in 1990 from Universitat Politècnica de Catalunya (UPC) in Spain focusing on computational mechanics on continuous media. He is currently the (full) Professor at Structural Engineering Division of Civil Engineering Department at University of Tehran and also was the former chairman of the division. He has extensive publications on his specialties that include fluid-structure interaction, structural dynamics, FEM, applied mathematics, and semi-analytical methods. He has published near 70 papers in the ISI-indexed international journals. 